Research Article

\title{
Coupled Effect of Curing Temperature and Moisture on THM Behavior of Cemented Paste Backfill
}

\author{
Wenyuan Xu $\mathbb{D}^{1,},{ }^{1,2}$ Runkang Zhao, ${ }^{3}$ Xiaocong Yang, ${ }^{1}$ Lijie Guo, ${ }^{1}$ Chaowu Xie, ${ }^{3}$ and Di Wu ${ }^{3,4}$ \\ ${ }^{1}$ BGRIMM Technology Group, Beijing, China \\ ${ }^{2}$ Civil and Resource Engineering School, University of Science and Technology Beijing, Beijing, China \\ ${ }^{3}$ School of Energy and Mining Engineering, China University of Mining and Technology-Beijing, Beijing, China \\ ${ }^{4}$ School of Civil, Environmental and Mining Engineering, The University of Western Australia, Perth, Australia \\ Correspondence should be addressed to Wenyuan Xu; xwy156@163.com
}

Received 20 August 2019; Revised 8 April 2020; Accepted 19 August 2020; Published 30 August 2020

Academic Editor: Carlos Chastre

Copyright $\odot 2020$ Wenyuan Xu et al. This is an open access article distributed under the Creative Commons Attribution License, which permits unrestricted use, distribution, and reproduction in any medium, provided the original work is properly cited.

\begin{abstract}
Cemented paste backfill (CPB), a mixture of tailings, binder, and water, is widely and continually utilized in underground mines for subsidence control and disposal of surface hazardous waste discharge. The mechanical strength of CPB, which is the key for the backfill structure to play the role of supporting overlying roof and controlling subsidence, is governed by complex factors (thermal, hydraulic, and mechanical loads), particularly strongly affected by the environmental conditions, such as ambient temperature and humidity. Thus, it is crucial to understand and assess the response of CPB subjected to the loads mentioned above, so as to better ascertain its performance and obtain a cost-effective, safe, and stable CPB structure. Accordingly, a coupled THM model is developed to describe and analyze the performance of CPB. Comparisons between model simulation and experiment data prove the capability of the developed model in predicting the evolutions of temperature and internal relative humidity, as well as stress-strain relation of CPB. The obtained results indicate that all these properties are significantly affected by ambient humidity and temperature.
\end{abstract}

\section{Introduction}

Mining operations inevitably cause the creation of large quantities of mined-out areas and mine wastes, such as tailings. Underground voids have become a threat to the safety of mining production of adjacent stopes. These voids can also cause ground subsidence or even collapse. Furthermore, the aboveground disposal of tailings occupies land and even causes serious geotechnical and environmental problems. As a solution to solve the consequent problems of mining industry, a technology of cemented paste backfill (CPB) is introduced to use tailings to fill underground openings. This solution is able to provide miners with safe working conditions, reduce ground surface deformation, and dispose mine wastes.

CPB is prepared by blending tailings, binder, water, and/ or additives (such as slag, fly ash, water reducer, and drag reducer). $\mathrm{CPBs}$ are being broadly and continually used as filling materials, which are placed underground for both mine waste management and ground control. Hence, CPB should be environment-friendly, exerting minimum contamination to subsurface environment. In addition, $\mathrm{CPB}$ should also possess good mechanical performance, providing support for mined-out stope [1-3].

Since CPB is cement-based material, its environmental and mechanical properties are significantly influenced by binder hydration, a chemical reaction between binder and water [4-6]. Binder hydration releases heat, consumes water, and generates hydration products, contributing to the developments of temperature, humidity, strength, permeability, and pore water pressure in CPB [7]. Obviously, the thermal, hydraulic, and mechanical (THM) behavior of CPB evolves with the process of binder hydration. The environmental and mechanical properties of $\mathrm{CPB}$ are related to its THM behavior. 
Once placed, the THM behavior of CPB is also affected by underground environment (including ambient temperature and humidity). Generally, a high ambient temperature can accelerate the binder hydration process to generate hydration products. Hydration products provide bonding between tailings particles, thus increasing mechanical stability of CPB. In addition, precipitation of hydration products in the pores of CPB leads to pore refinement and porosity reduction, resulting in the decrease of hydraulic permeability and thus the improvement of environmental friendliness of CPB [8].

Several studies investigated the thermal, hydraulic, and mechanical responses of $\mathrm{CPB}$ to chemistry (binder hydration) and curing conditions (e.g., curing temperature). For instance, Kesimal et al. presented the influence of various binder types on mechanical performance of CPB [9]. Walske et al. carried out an experiment in laboratory to reveal the coupled effect of curing temperature and stress conditions on mechanical behaviors of CPB [10]. Abdul-Hussain and Fall set up an experimental program to analyze the thermal, hydraulic, and mechanical performance of CPB by monitoring its suction, temperature, and uniaxial compressive strength (UCS) evolutions [11]. Furthermore, Hou et al. studied the influence of binder content on temperature and internal strain evolution of $\mathrm{CPB}$ and found that the evolution of internal strain and settlement was an indicator of the transformation in different stages during the hydration process [12]. Yilmaz et al. investigated the effects of curing and stress conditions on hydromechanical, geotechnical, and geochemical properties of CPB and pointed that, for a given backfill recipe, consolidated samples always present better strengths compared to those obtained from mouldunconsolidated samples [13].

Jiang et al. conducted an experimental study to investigate the yield stress of $\mathrm{CPB}$ and its evolution with time when exposed to subzero environmental temperatures [14]. Li et al. explored the influence of bentonite on the thermal and moisture diffusion of sand-based backfill materials in cooling and heating modes in a lab-scale setup [15].

Recently, multiphysics modeling has become an effective approach for studying the coupled behavior of CPB. For instance, Pokharel and Fall proposed a coupled model to assess the thermal and hydraulic behaviors of CPB [16]. Jiang et al. established a coupled THC model to analyze the thermal and hydraulic behaviors of CPB [14]. Wu et al. presented a multiphysics model to predict the coupled THMC responses of $\mathrm{CPB}$ to different loading conditions [17].

As discussed above, former researchers have conducted significant experimental and numerical studies to describe and analyze the coupled behaviors of CPB. However, the effect of (curing) humidity was not considered in their experiments or numerical models. Due to these limitations, this study intends to develop a numerical model in consideration of moisture and conducts an experiment on $\mathrm{CPB}$ under different curing humidity. The developed model will be validated against the experiment, based on the comparison of the modeling and testing results. In this paper, the influences of temperature and other factors of the mechanical strength of $\mathrm{CPB}$ are considered, and the influence of humidity is emphasized, which is of great significance to understand the strength development of CPB in situ stope.

\section{Model Development}

2.1. Thermal Process. The primary thermal processes include binder hydration (an exothermic reaction) and heat conduction between $\mathrm{CPB}$ and its surroundings. In order to describe the thermal processes, the following equation is used:

$$
(\rho C)_{\mathrm{eq}} \frac{\partial T}{\partial t}+\nabla q=Q_{H}
$$

where $T$ is temperature, $t$ is time, $(\rho C)_{\mathrm{eq}}$ is the equivalent volumetric heat capacity of $\mathrm{CPB}$ at constant pressure, $q$ is the conductive heat flux vector, and $Q_{H}$ represents the heat generated by binder hydration.

The conductive heat flux vector $q$ can be expressed as [18]

$$
q=-k_{\mathrm{eq}} \cdot \nabla T
$$

where $k_{\mathrm{eq}}$ is the equivalent thermal conductivity of CPB:

$$
k_{\mathrm{eq}}=\phi k_{s}+(1-\phi) k_{f}
$$

where $\phi$ is the porosity of $\mathrm{CPB}$ and $k_{f}$ and $k_{s}$ represent the thermal conductivity values of the fluid and the solid matrix, respectively.

$Q_{H}$ can be obtained by the following equation:

$$
Q_{H}=C_{b} \cdot q_{h},
$$

where $C_{b}$ is the content of binder, which is used to prepare $\mathrm{CPB}$, and $q_{h}$ denotes the binder hydration heat produced per unit time by weight $[19,20]$ :

$$
q_{h}=q_{m} \cdot a \cdot\left[\sin (\pi \cdot \alpha)^{b}\right] \cdot \exp (-c \cdot \alpha) \cdot \exp \left[\frac{E_{A}}{R} \cdot\left(\frac{1}{T_{r}}-\frac{1}{T_{c}}\right)\right],
$$

where $q_{m}$ is the maximum rate of heat production at the temperature of $20^{\circ} \mathrm{C} ; a, b$, and $c$ are parameters determined by experiments; $\alpha$ is the degree of binder hydration; $T_{r}$ is the reference temperature; $T_{c}$ is the temperature of $C P B ; R$ is the universal gas constant; and $E_{A}$ is the apparent activation energy, which can be obtained according to a reference study [21].

The porosity of CPB evolves with the progress of binder hydration [7]:

$$
\phi=\phi_{0}+\lambda \alpha
$$

where $\phi_{0}$ is the initial porosity of CPB and $\lambda$ is an experimentally determined parameter.

The degree of binder hydration $(\alpha)$ can be calculated as follows [22-24]: 


$$
\alpha=\alpha_{u} \cdot \exp \left[-\left(\frac{\tau}{t_{e}}\right)^{\beta}\right],
$$

where $\alpha_{u}$ is the ultimate degree of binder hydration; $\tau$ and $\beta$ are the time parameter and shape parameter of the binder hydration, respectively; and $t_{e}$ is the equivalent age:

$$
t_{e}=\int_{0}^{t} \exp \left[\frac{E_{A}}{R} \cdot\left(\frac{1}{T_{r}}-\frac{1}{T_{c}}\right)\right] \mathrm{d} t .
$$

The ultimate degree of binder hydration can be expressed as follows [25]:

$$
\alpha_{u}=\frac{1.031 \cdot r}{0.194+r} \leq 1,
$$

where $r$ is the ratio of water to binder.

In consideration of the effect of humidity on the binder hydration process, equation (7) can be rewritten as [26]

$$
\alpha=\alpha_{u} \cdot \exp \left[-\left(\frac{\tau}{t_{e}}\right)^{\beta}\right] \cdot C_{H} \cdot 100,
$$

where $C_{H}$ is a coefficient indicating the influence of humidity [26]:

$$
C_{H}= \begin{cases}0.0051 H+0.5292, & H<95 \%, \\ 1, & H \geq 95 \%,\end{cases}
$$

where $H$ is the internal relative humidity (\%) of CPB.

2.2. Hydraulic Process. With the proceeding of binder hydration in $\mathrm{CPB}$, the content of water decreases due to the combined influence of hydration's consumption of water and moisture diffusion between $\mathrm{CPB}$ and its surrounding environment and also due to the water advection through the rock mass, barricade, and mine air. Therefore, the governing equation of the internal relative humidity can be derived as [27]

$$
\frac{\partial H}{\partial t}=\nabla \cdot[D(H) \nabla H]+\frac{\partial L_{H}}{\partial t},
$$

where $L_{H}$ denotes the loss of water caused by binder hydration; $D(H)$ is the moisture diffusion coefficient [27]:

$$
D(H)=D_{M}\left[\gamma+\frac{1-\gamma}{1+\left((1-H) /\left(1-H_{C}\right)\right)^{\theta}}\right],
$$

where $D_{M}$ represents the moisture diffusion coefficient of $\mathrm{CPB}$ under the condition of saturation, $H_{C}$ is the critical value of the internal relative humidity, and $\gamma$ and $\theta$ are the parameters determined by experiment. The values used in this study for $D_{M}, H_{C}, \gamma$, and $\theta$ are $0.24,0.75,0.05$, and 16 , respectively, based on a reference study [27].

$H_{L}$ in equation (11) can be expressed as follows [28]:

$$
L_{H}= \begin{cases}0, & \alpha \leq \alpha_{c}, \\ \left(1-H_{s u}\right)\left(\frac{\alpha-\alpha_{c}}{\alpha_{u}-\alpha_{c}}\right)^{\omega}, & \alpha>\alpha_{c},\end{cases}
$$

where $H_{s u}$ represents the internal relative humidity considering self-desiccation at the ultimate degree of hydration; $\alpha_{c}$ is the critical hydration degree at which the humidity of CPB starts to decrease from $100 \%$ level; $\omega$ is an experimental constant. The values of $H_{s u}, \alpha_{c}$, and $\omega$ are $0.75,0.85$, and 6.07, respectively, based on a reference study [29].

2.3. Mechanical Process. As discussed above, the thermal and hydraulic processes occur in CPB. When a CPB is placed underground, it is also subjected to a mechanical load. As a result, the total strain of a placed $\mathrm{CPB}$ can be expressed as follows:

$$
\varepsilon=\varepsilon_{e}+\varepsilon_{p}+\varepsilon_{t}+\varepsilon_{m},
$$

where $\varepsilon$ is the total strain and $\varepsilon_{e}, \varepsilon_{p}$, $\varepsilon_{t}$, and $\varepsilon_{m}$ are the elastic strain, plastic strain, thermal strain, and moisture strain, respectively.

The constitutive relationship between the effective stress and elastic strain of a CPB is expressed in the following equation based on the assumption that the $\mathrm{CPB}$ is isotropic in this study:

$$
\sigma_{\text {eff }}=D \varepsilon_{e}=D\left(\varepsilon-\varepsilon_{p}-\varepsilon_{t}-\varepsilon_{m}\right),
$$

where $\sigma_{\text {eff }}$ is the effective stress and $D$ is the elasticity matrix:

$$
\begin{aligned}
& D=\left[\begin{array}{cccccc}
\lambda+2 \mu & \lambda & \lambda & 0 & 0 & 0 \\
\lambda & \lambda+2 \mu & \lambda & 0 & 0 & 0 \\
\lambda & \lambda & \lambda+2 \mu & 0 & 0 & 0 \\
0 & 0 & 0 & \mu & 0 & 0 \\
0 & 0 & 0 & 0 & \mu & 0 \\
0 & 0 & 0 & 0 & 0 & \mu
\end{array}\right], \\
& \lambda=\frac{E v}{(1+v)(1-2 v)}, \\
& \mu=\frac{E}{2(1+v)},
\end{aligned}
$$

where $E$ is the elastic modulus and $v$ is Poisson's ratio, and they both vary with the progress of binder hydration.

The elastic modulus can be calculated by the following equation [20]: 


$$
E=\left(\frac{\alpha-\alpha_{0}}{\alpha_{u}-\alpha_{0}}\right)^{X} \cdot E_{u}
$$

where $E_{u}$ is the ultimate elastic modulus; $\alpha_{0}$ refers to the reference hydration degree, which means that, below a threshold value, no elastic modulus development occurs; $X$ is a material constant that depends on the mix components of $\mathrm{CPB}$. The values used in this study for $E_{u}, \alpha_{0}$, and $X$ are $1900 \mathrm{MPa}, 0.09$, and 2.199, respectively, based on a reference study [30].

The evolution of Poisson's ratio with the binder hydration degree can be expressed as follows [31-34]:

$$
v=0.5 \cdot \exp \left(Y_{1} \alpha\right)+Y_{2} \cdot \alpha^{Y_{3}} \cdot \exp \left(Y_{4} \alpha^{Y_{5}}\right)
$$

where $Y_{1}, Y_{2}, Y_{3}, Y_{4}$, and $Y_{5}$ are the fitting parameters, which are $-0.2,-15000,7,-11$, and 0.7 , respectively, according to a reference study [30].

2.3.1. Plastic Strain. The plastic strain can be calculated by the following equations [30]:

$$
\begin{aligned}
d \varepsilon_{p} & =\frac{\left(\eta \delta+\left(S / 2 \sqrt{J_{2}}\right)\right) D d \varepsilon+(\partial F / \partial \alpha) d \alpha}{\left(\eta \delta+\left(S / 2 \sqrt{J_{2}}\right)\right) D-\left(\partial F / \partial \varepsilon_{p}\right)}, \\
F & =\sqrt{J_{2}}+\eta\left(I_{1}-C\right)=0, \\
I_{1} & =\sigma_{1}+\sigma_{2}+\sigma_{3}, \\
J_{2} & =\frac{1}{2} S_{i j} S_{i j}, \\
S_{i j} & =\sigma_{i j}-\frac{I}{3 \delta_{i j}}, \\
\eta & =\frac{2 \sin \varphi}{\sqrt{3}(3+\sin \varphi)} C=3 c_{h} \cot \varphi, \\
\varphi & =M_{1} \alpha^{M_{2}}+M_{3} \alpha, \\
c_{h} & =N_{1} \alpha^{N_{2}},
\end{aligned}
$$

where $S_{i j}$ is the stress deviator; $\delta_{i j}$ is the Kronecker delta $\left(\delta_{i i}=1 ; \delta_{i \neq j}=0\right) ; \varphi$ is the internal friction angle; $c_{h}$ is the cohesion; and $M_{1}, M_{2}, M_{3}, N_{1}$, and $N_{2}$ are separately the fitting constants, which are $-176.9^{\circ}, 2,174.2^{\circ}, 478 \mathrm{kPa}$, and 3.3 , on the basis of the study in [30].

2.3.2. Thermal Strain. The thermal strain can be derived by the following equation [35]:

$$
\mathrm{d} \varepsilon_{t}=\beta_{t} \cdot \mathrm{d} T \cdot I
$$

where $I$ denotes the second-order volumetric unity tensor and $\beta_{t}$ is the linear thermal expansion coefficient [36-38]:

$$
\beta_{t}=\frac{2 v_{t}^{2} \cdot\left(1 / C_{b}-1\right)}{\left[r v_{w}+v_{c}\right] \cdot\left\{1+\left[N_{3} \cdot(1-\psi)^{N_{4}}\right] / E_{t}\right\}+2 v_{t} \cdot\left(1 / C_{b}-1\right)},
$$

$$
\begin{aligned}
\psi & =\frac{r v_{w}-\left(v_{c c w}+v_{a w}\right) R_{c c w / h c} \cdot \alpha}{r v_{w}+v_{c c w}+\left(1 / C_{b}-1\right) \cdot v_{c g}} \\
R_{c c w / h c} & =0.187 p_{C_{3} S}+0.158 p_{C_{2} S}+0.665 p_{C_{3} A} \\
& +0.213 p_{C_{4} A F}
\end{aligned}
$$

where $v_{t}, v_{w}$, and $v_{c}$ are separately the specific volumes of tailings, water, and cement, $N_{3}$ and $N_{4}$ are the fitting parameters (the values used for them are $46.03 \mathrm{GPa}$ and 3.16, respectively, based on the study in [17]), $E_{t}$ is the elastic modulus of tailings used, $p_{i}$ is the weight proportion of the clinker composition, and $v_{c c w}$ and $v_{a w}$ are, respectively, the specific volumes of chemically combined water and absorbed water, which are $0.72 \mathrm{~cm}^{3} / \mathrm{g}$ and $0.90 \mathrm{~cm}^{3} / \mathrm{g}$ according to a reference study [39].

2.3.3. Moisture Strain. The moisture strain can be expressed as follows on the basis of the studies in [40-42]:

$$
\begin{aligned}
\varepsilon_{m} & =\zeta\left[1-\sqrt[3]{1-\left(V_{c s}-V_{c s 0}\right)}\right]+\frac{S_{F} \rho_{w} R T}{3 M_{w}}\left(\frac{1}{K_{S}}-\frac{1}{K}\right) \ln H \\
V_{c s} & =0.2(1-Z) \alpha \\
V_{c s 0} & =0.2(1-Z) \alpha_{0} \\
S_{F} & =\frac{Z-0.7(1-Z) \alpha}{Z-0.5(1-Z) \alpha} \\
Z & =\frac{r}{r+\rho_{w} / \rho_{c}} \\
K & =\frac{E}{3(1-2 v)}
\end{aligned}
$$

where $\zeta$ denotes the influencing factor of stiffness (it is valued as 0.03 in this study); $\rho_{w}$ and $\rho_{c}$ are the densities of water and cement, respectively; $M_{w}$ is the molar weight of water $(0.01802 \mathrm{~kg} / \mathrm{mol})$; and $K_{S}$ is the bulk modulus of solid material.

The above mathematical modeling procedure indicates that the thermal, hydraulic, and mechanical processes can be mutually coupled with each other by the evolution of the binder hydration degree $(\alpha)$ with time.

\section{Experimental Programs}

3.1. Materials. The CPB materials are prepared by mixing the tailings, binder, and water. The tailings used are obtained from an iron mine that is located at high altitude region of 


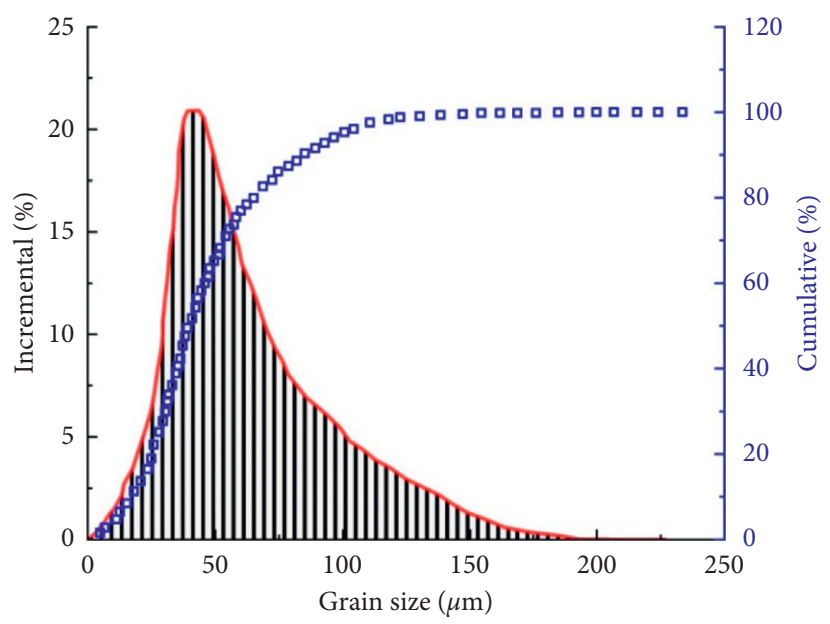

IIIII Incremental

$\square$ Cumulative

FIgURE 1: Grain size distribution of the tailings used.

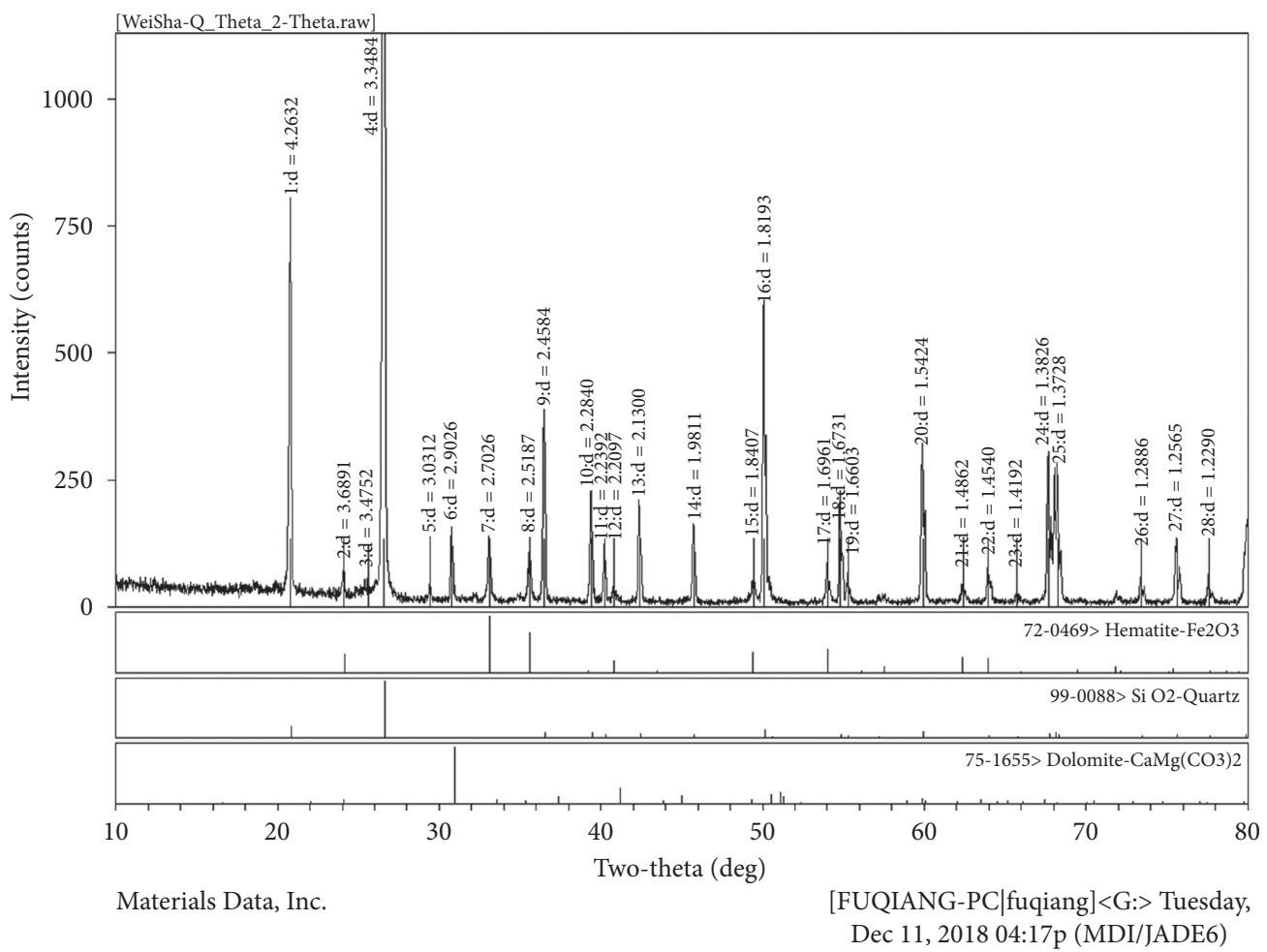

FIGURE 2: XRD profiles of the tailings.

western China. The binder used is ordinary Portland cement 425\#, and tap water is used. Figure 1 shows the particle size composition of the tailings used; the median grain size (d50) of tailings is $37.5 \mu \mathrm{m}$. Figure 2 presents the main mineral constituents (quartz, dolomite, and hematite) of the tailings.

3.2. Testing Methods. A series of CPB specimens with the ratios of binder to tailings $(b / t)$ of $1 / 6,1 / 8$, and $1 / 10$ and solid concentrations of $70 \%, 72 \%$, and $74 \%$ were prepared for the test, as presented in Table 1. For each group of CPB samples, four $\mathrm{CPBs}$ were prepared and then cured in the ambient environment with temperature of $10^{\circ} \mathrm{C}, 20^{\circ} \mathrm{C}$, and $30^{\circ} \mathrm{C}$ and humidity of $45 \%, 70 \%$, and $95 \%$ for a period of 28 days. During the curing process, one of the four CPBs was subjected to the investigation of the evolutions of temperature and internal relative humidity versus time. After the process of 28 days' curing, the other three CPBs were subjected to UCS tests for obtaining stress-strain relations, and the average value was used. Figure 3 presents the experimental procedure.

The CPB sample had a dimension of $10 \mathrm{~cm} \times 10 \mathrm{~cm} \times 10 \mathrm{~cm}$ in length $\times$ width $\times$ height. A 
TABLE 1: Groups of the CPB specimens used for tests.

\begin{tabular}{lccccc}
\hline Group & Solid content (mass $\%)$ & $b / t$ & Curing age $(\mathrm{d})$ & Curing temperature $\left({ }^{\circ} \mathrm{C}\right)$ & Curing humidity $(\%)$ \\
\hline 1 & 70 & $1 / 10$ & 28 & 30 & 70 \\
2 & 72 & $1 / 10$ & 28 & 30 & 70 \\
3 & 72 & $1 / 8$ & 28 & 10 & 45 \\
4 & 72 & $1 / 8$ & 28 & 20 & 95 \\
5 & 74 & $1 / 6$ & 28 & 20 & 95 \\
6 & 74 & $1 / 8$ & 28 & 95 \\
\hline
\end{tabular}

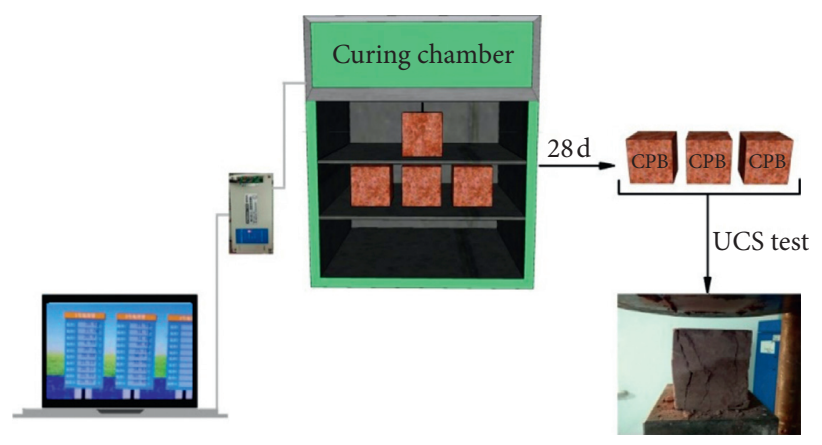

FIgURE 3: Experimental procedure.

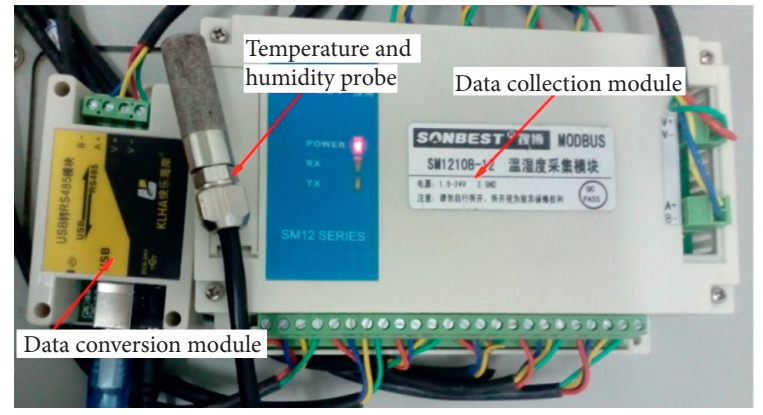

FIGURE 4: Temperature and humidity measurement system.

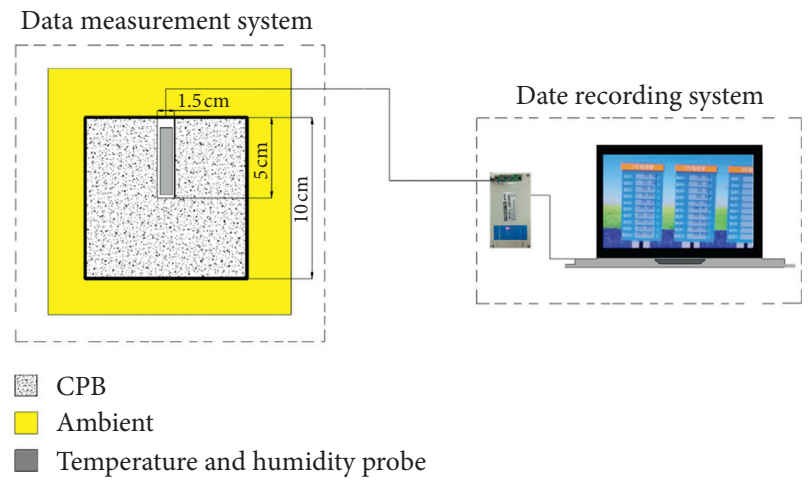

Figure 5: Schematic diagram of the experimental program for monitoring.

cylindrical temperature and humidity probe (with a dimension of $3 \mathrm{~cm} \times 1.1 \mathrm{~cm}$ in height $\times$ diameter as presented in Figure 4) was inserted into the $\mathrm{CPB}$ for monitoring its evolution of temperature and internal relative humidity with time, as shown in Figure 5.

The stress-strain relationships of the $\mathrm{CPB}$ samples were obtained by a rock mechanics testing apparatus (type: YAW-
600), which had a maximum load of $600 \mathrm{kN}$. During the process of UCS testing, the compressive loading rate of the rock mechanics testing apparatus was set as constant $(2 \mathrm{~mm} / \mathrm{min})$.

\section{Validation of the Developed Model}

The developed model is implemented to predict the evolution of temperature, internal relative humidity, and stressstrain relationship of the $\mathrm{CPB}$ specimens. The simulation and prediction results of the developed model are compared with the experimentally tested data for verifying the validity and applicability of the model.

Table 2 shows the main input parameters, boundary conditions, and initial values used for the numerical model simulation. The selection of curing temperature and humidity parameters is based on the actual stope conditions of typical underground mines, and the material properties such as conductivity, porosity, and density are measured by experiments.

4.1. Validation of Evolution of Internal Relative Humidity of $C P B$. Figure 6 demonstrates a comparison between the numerically simulated outcomes and experimentally measured data of the evolution of internal relative humidity of $\mathrm{CPB}$ versus curing time. It can be noticed that the model prediction results agree well with the experimental testing data, except for some misfits that are acceptable. The desired consistency between the model simulation and test observation proves the validity of the developed model in predicting the evolution of internal relative humidity of $\mathrm{CPB}$.

From Figure 6, it can also be found that, with the elapse of curing time, the evolution of internal relative humidity of $\mathrm{CPB}$ can be approximately divided into three stages: the saturation stage, sharp decline stage, and stable stage, as presented in Figure 7 . There is enough water involved in the binder hydration 
TABLE 2: Parameters and conditions used for model verification.

\begin{tabular}{lc}
\hline Parameters and conditions & Values \\
\hline Curing temperature $\left({ }^{\circ} \mathrm{C}\right)$ & $30 ; 30 ; 10 ; 10 ; 20 ; 20$ \\
Curing age $(\mathrm{d})$ & 28 \\
Curing humidity $(\%)$ & $70 ; 70 ; 45 ; 95 ; 95 ; 95$ \\
Thermal conductivity of the solid matrix $(\mathrm{W} /(\mathrm{m} \cdot \mathrm{K}))$ & 3.15 \\
Initial porosity of the CPB samples & 0.45 \\
Specific heat of the solid matrix $(\mathrm{J} /(\mathrm{kg} \cdot \mathrm{K}))$ & 1300 \\
Density of the solid matrix $\left(\mathrm{kg} / \mathrm{m}^{3}\right)$ & 2200 \\
Density of liquid water $\left(\mathrm{kg} / \mathrm{m}^{3}\right)$ & 1000 \\
Specific heat of liquid water $(\mathrm{J} /(\mathrm{kg} \cdot \mathrm{K}))$ & 4200 \\
Initial temperature of the $\mathrm{CPB} \mathrm{samples}\left({ }^{\circ} \mathrm{C}\right)$ & $30 ; 30 ; 10 ; 10 ; 20 ; 20$ \\
Initial humidity of the $\mathrm{CPB} \mathrm{samples}(\%)$ & 100 \\
Initial displacement field $(\mathrm{m})$ & 0 \\
Initial structural velocity field $(\mathrm{m} / \mathrm{s})$ & 0 \\
Top surface & Confined deformation \\
Lateral sides & Free \\
Bottom side & Fixed \\
Volume force & Gravity \\
\hline
\end{tabular}

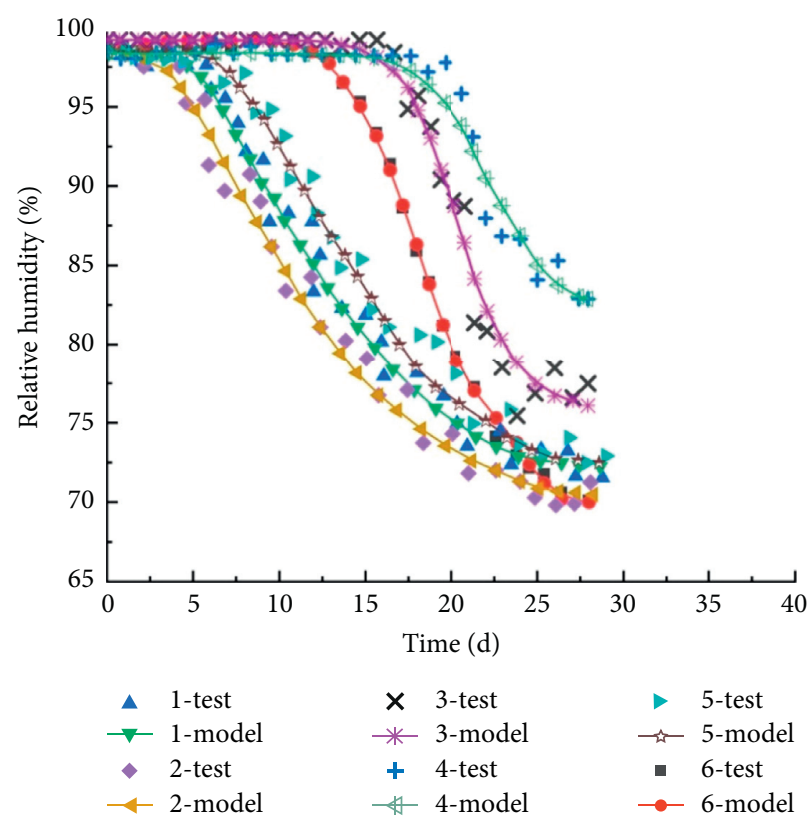

Figure 6: Comparison between predicting and testing results of internal relative humidity of CPB.

process during the saturation stage. When it comes to the sharp decline stage, plenty of water is consumed because of the combined effect of binder hydration and evaporation. The water content substantially stays constant during the stable stage, due to the fact that the binder hydration process has almost finished and the pores within CPB have been filled by hydration products, which prevent water evaporating outside the CPB.

Through the comparison of the results of groups 1 and 2, it can be clearly seen that a higher solid content is associated with a lower internal relative humidity of $\mathrm{CPB}$. The reason is obvious that a higher solid content signifies a lower water content. From the contrast between the results of groups 3 and 4 , it is noticed that increasing the curing humidity also increases the internal relative humidity of $\mathrm{CPB}$. This may be due to the moisture gradient between the CPB and its curing ambient. A higher moisture gradient makes more water evaporate from the CPB to its surroundings. Besides, by comparing the results of group 5 with those of group 6, it is observed that a higher ratio of binder to tailings leads to a greater decrease in the internal relative humidity of $\mathrm{CPB}$. This is ascribed to the fact that a higher content of binder consumes more water.

The CPB sample of group 4 is selected as an example to investigate the distribution of internal relative humidity within $\mathrm{CPB}$, as shown in Figure 8.

From Figure 8, it can be seen that the CPB sample is in saturation state at the beginning of the curing time and its internal relative humidity is 1 (Figure $8(\mathrm{a})$ ). Compared with the interior relative humidity of the $\mathrm{CPB}$ sample, the relative humidity of the edge of the CPB sample is relatively lower because of the moisture migration between the CPB and its surrounding ambient (with a humidity of 95\%). With the elapse of curing time, the interior relative humidity of the 


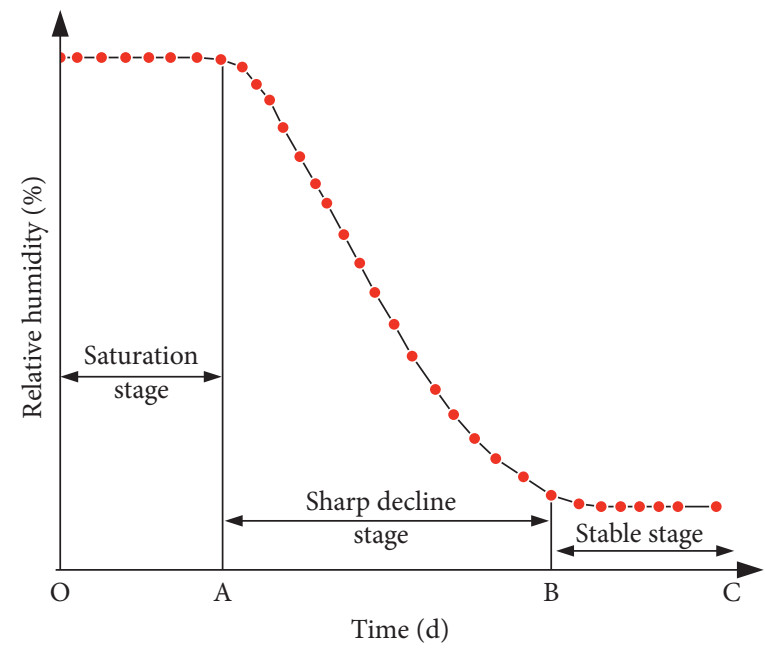

FIGURE 7: Stages of the internal relative humidity evolution of CPB with time.

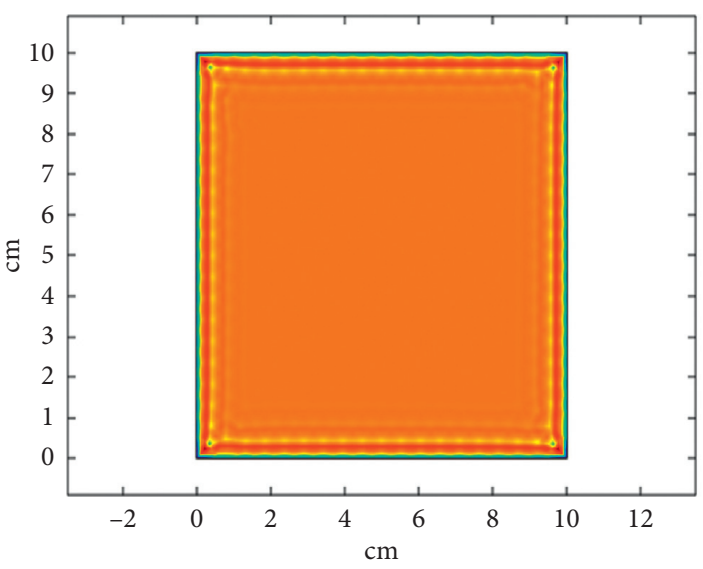

(a)

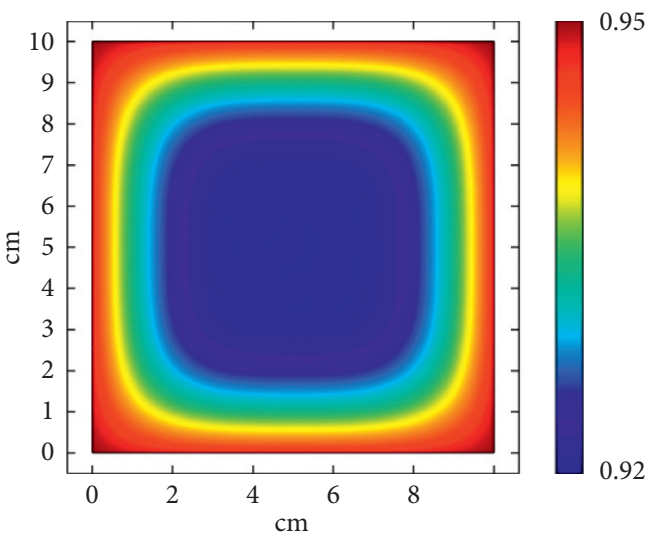

(c)
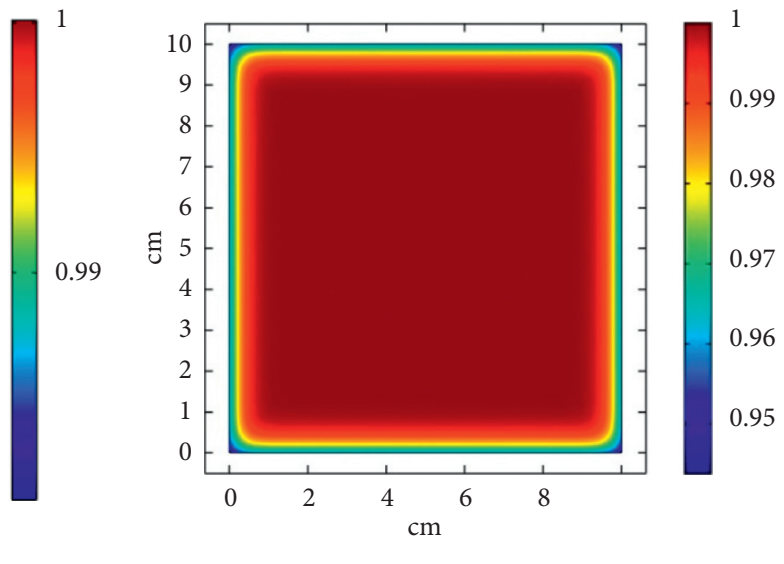

(b)

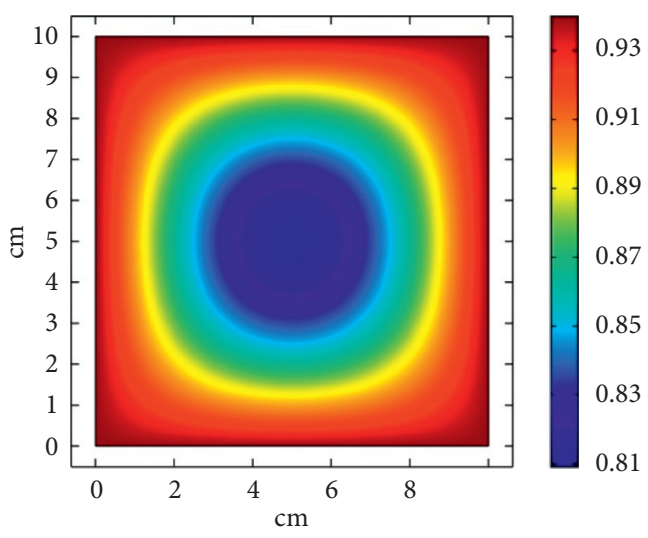

(d)

Figure 8: Simulated evolution of internal relative humidity in the CPB sample at different curing ages: (a) $0 \mathrm{~d}$; (b) $1 \mathrm{~d}$; (c) $23 \mathrm{~d}$; (d) $28 \mathrm{~d}$.

$\mathrm{CPB}$ sample gradually decreases. This is ascribed to water consumption induced by binder hydration in the CPB. When it comes to the late age, the process of binder hydration is over, and the relative humidity of the edge of the $\mathrm{CPB}$ becomes approximate to the curing humidity.
4.2. Validation of Temperature Development in CPB. Figure 9 presents a comparison between the simulation results and measured data of the temperature development within the CPB samples versus curing time. It can be seen that the predicted evolution of temperature is in good 


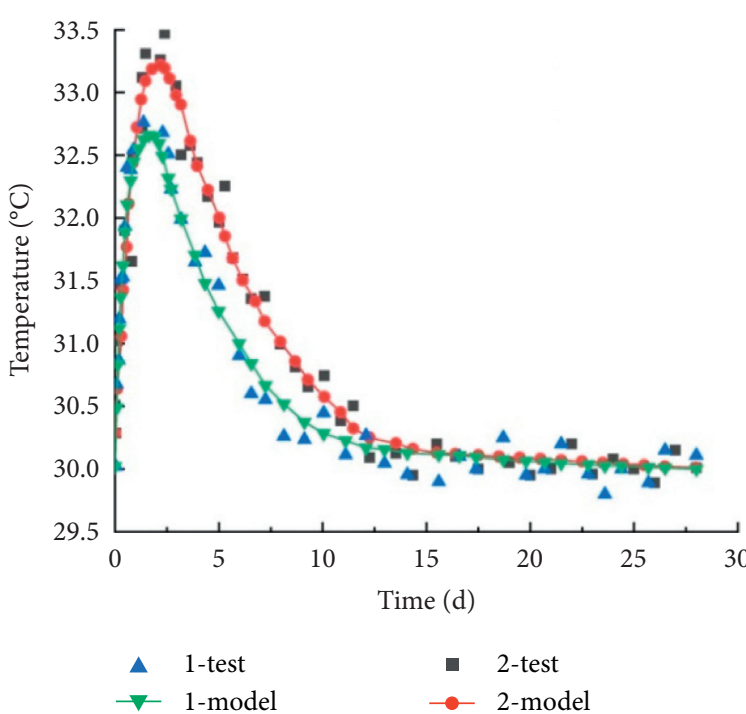

(a)

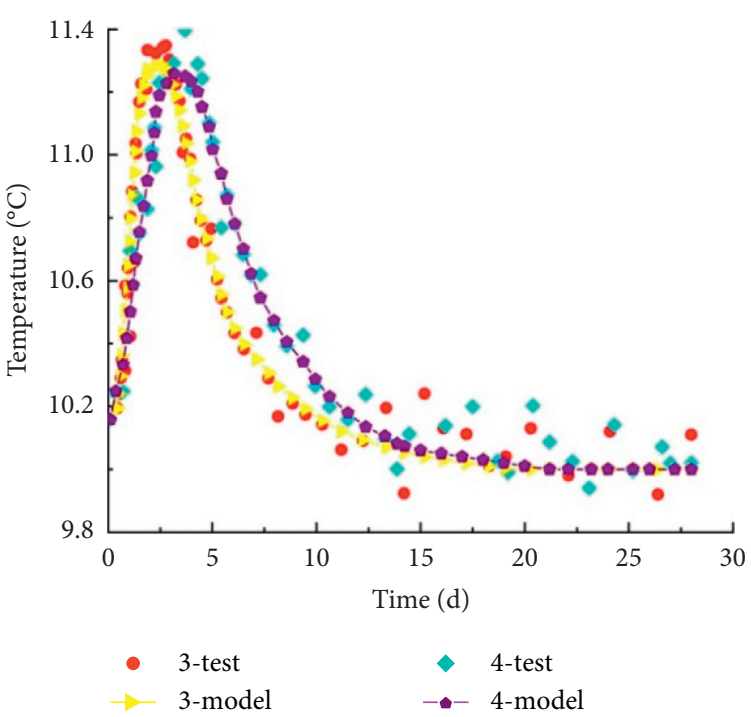

(b)

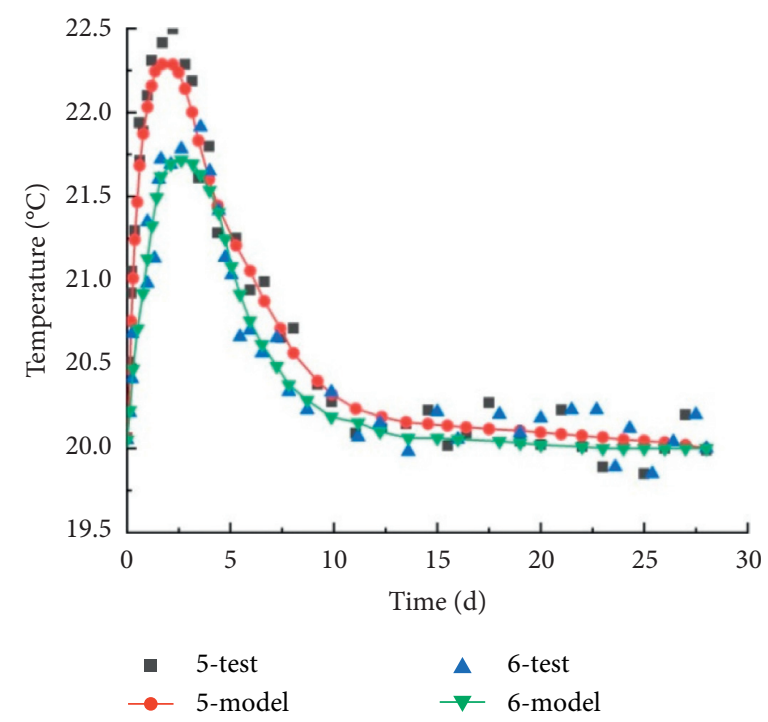

(c)

FIGURE 9: Comparison between predicting and testing results of temperature development in CPB.

agreement with the test results, except for some misfits that may be due to the varied curing conditions.

From Figure 9, it can be found that the temperature of $\mathrm{CPB}$ increases dramatically to the maximum during the early age. This is because of the heat generated by the process of binder hydration. It can also be noticed that a higher curing temperature is associated with a higher temperature rise in the $\mathrm{CPB}$. With the elapse of curing time, when the binder hydrates completely, no more heat is generated and the temperature of CPB decreases until a balanced temperature is reached due to the thermal exchange.

As expected, Figure 9 can also indicate that a higher temperature increase in the $\mathrm{CPB}$ is associated with a lower water-to-binder ratio $(w / b)$ used. This is due to the fact that a lower w/b means more binder is used, releasing more heat to increase the temperature of CPB. Ambient humidity also affects the temperature development of $\mathrm{CPB}$, since it is in relation to the moisture exchange between the $\mathrm{CPB}$ and its curing ambient. The increase of internal relative humidity of $\mathrm{CPB}$ can lead to its temperature rise, through accelerating the binder hydration to generate heat, based on equation (10).

4.3. Validation of Stress-Strain Relationship of CPB. A comparison of the stress-strain relation of CPB between the predicted results and tested values is demonstrated in Figure 10. It can be seen that the simulated stress-strain relationship is in good agreement with the test data in terms of both maximum values and evolution trend. The comparison results indicate that the proposed model can be used to predict the stress development in the CPB versus strain.

From Figure 10, it can also be found that the stress-strain relation of $\mathrm{CPB}$ is affected by solid content, binder-to-tailings ratio, and curing humidity. As expected, a higher stress is 


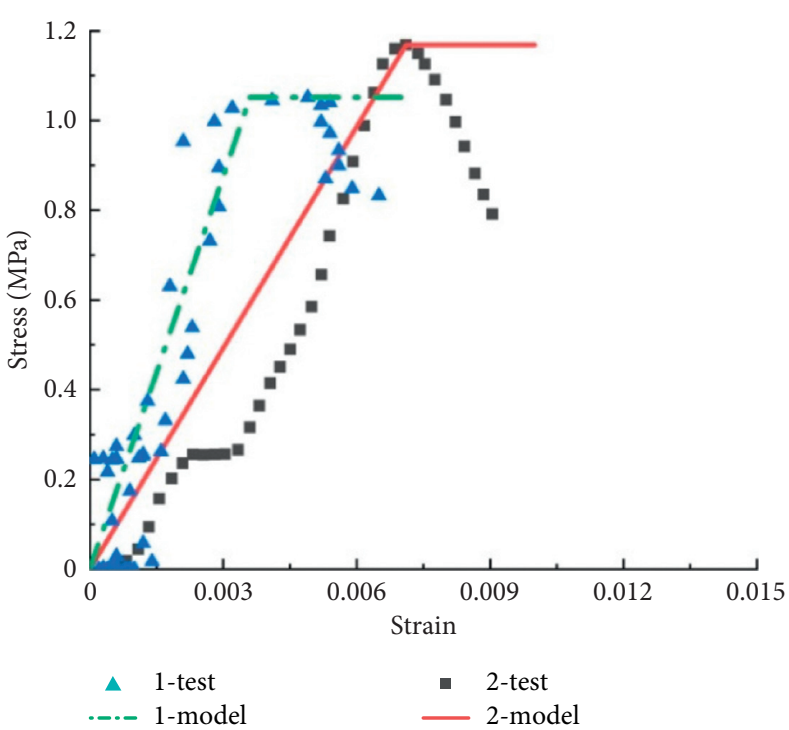

(a)

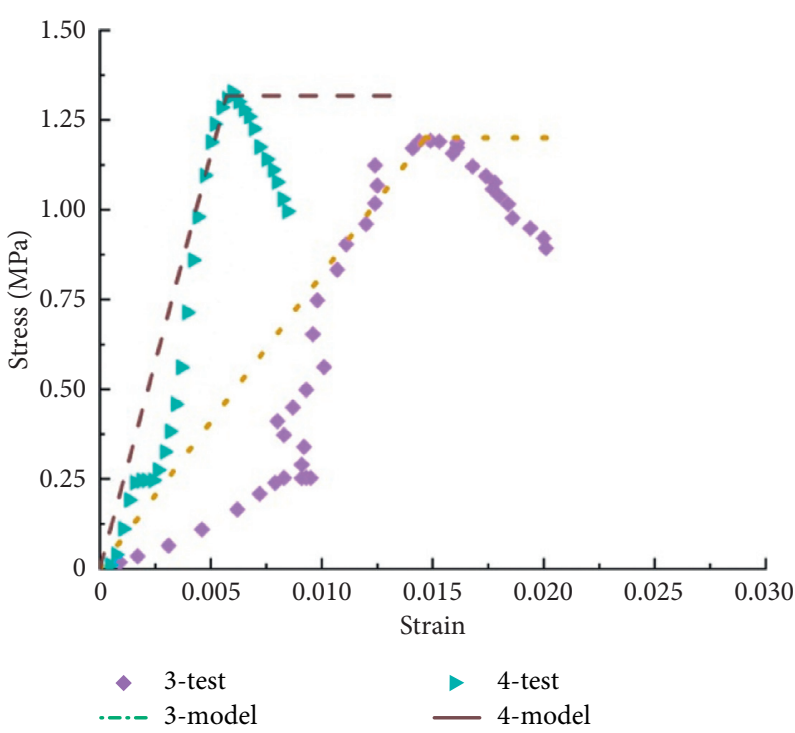

(b)

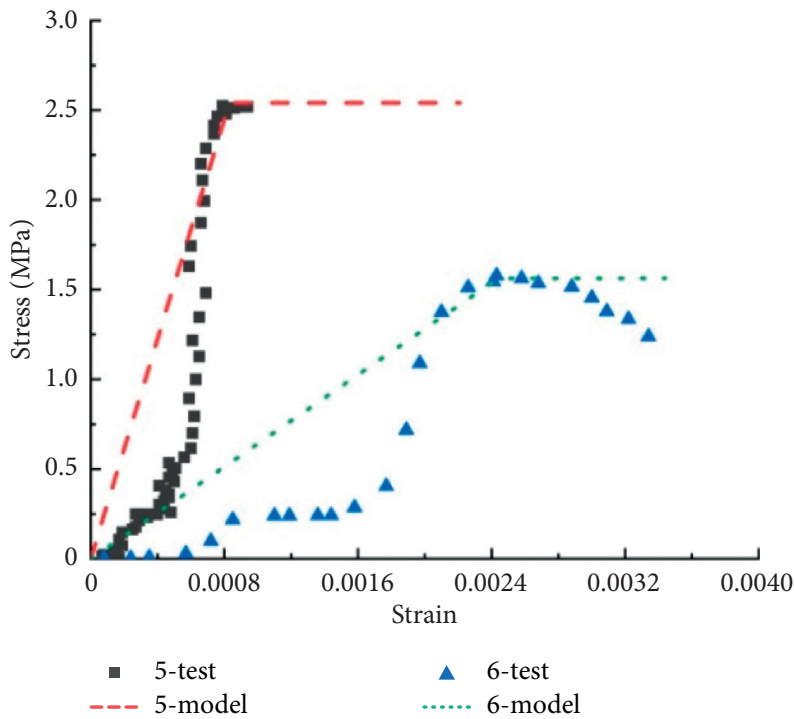

(c)

FIGURE 10: Comparison of stress-strain relationship of CPB between model simulation and experiment measurement.

developed in the CPB because higher solid content and binderto-tailings ratio are used. Moreover, increasing the curing humidity leads to the reduction of the UCS of CPB. This is due to the fact that the CPB cured with higher ambient humidity has a higher pore water pressure, and thus a lower effective stress developed.

\section{Conclusions}

In this study, comprehensive laboratory experiments and numerical analyses based on a validated model developed are conducted to investigate the thermal, hydraulic, and mechanical performance of CPB. Based on the obtained results, the conclusions can be drawn as follows:

(i) The developed model simulates the thermal distribution, temperature development, internal relative humidity development and distribution, and stress-strain relationship of CPB. The validity of this model is verified by a comparison between the simulation results and test data.

(ii) The curing conditions can significantly affect the performance of CPB. Increasing the curing temperature can accelerate the binder hydration process to consume water and thus lead to a decrease in the internal relative humidity of $\mathrm{CPB}$ and an increase in the strength development of CPB. The curing humidity can also exert influence on the behavior of $\mathrm{CPB}$ by the interaction of moisture between the CPB and its surrounding ambient.

(iii) This study can contribute to a better understanding of the THM responses of CPB to different ambient conditions. As a result, corresponding designs such as adjusting the solid content and binder-to-tailings 
ratio of $\mathrm{CPB}$ can be implemented according to the effect of ambient condition on the CPB.

\section{Data Availability}

All data used to support the findings of this study are available from the corresponding author upon request.

\section{Conflicts of Interest}

The authors declare that there are no conflicts of interest.

\section{Acknowledgments}

Financial support from the National Natural Science Foundation of China (Grants nos. 51774040 and 51804031) and the Youth Science and Technology Innovation Fund of BGRIMM Technology Group (Grant no. QCJ201804) is gratefully acknowledged.

\section{References}

[1] O. Nasir and M. Fall, "Shear behaviour of cemented pastefillrock interfaces," Engineering Geology, vol. 101, no. 3-4, pp. 146-153, 2008.

[2] E. Yilmaz, A. Kesimal, and B. Ercidi, "Strength development of paste backfill simples at Long term using different binders," in Proceedings of the 8th Symposium International Symposium on Mining with Backfill (MineFill 04), China, pp. 281-285, Beijing, China, August 2004.

[3] N. Sivakugan, R. M. Rankine, K. J. Rankine, and K. S. Rankine, "Geotechnical considerations in mine backfilling in Australia," Journal of Cleaner Production, vol. 14, no. 12-13, pp. 1168-1175, 2006.

[4] D. Wu, M. Fall, and S. J. Cai, "Coupling temperature, cement hydration and rheological behaviour of fresh cemented paste backfill," Minerals Engineering, vol. 42, pp. 76-87, 2013.

[5] F. Cihangir, B. Ercikdi, A. Kesimal, S. Ocak, and Y. Akyol, "Effect of sodium-silicate activated slag at different silicate modulus on the strength and microstructural properties of full and coarse sulphidic tailings paste backfill," Construction and Building Materials, vol. 185, pp. 555-566, 2018.

[6] W. Li and M. Fall, "Sulphate effect on the early age strength and self-desiccation of cemented paste backfill," Construction and Building Materials, vol. 106, pp. 296-304, 2016.

[7] N. Abdul-Hussain and M. Fall, "Unsaturated hydraulic properties of cemented tailings backfill that contains sodium silicate," Engineering Geology, vol. 123, no. 4, pp. 288-301, 2011.

[8] A. Ghirian and M. Fall, "Coupled thermo-hydro-mechanicalchemical behaviour of cemented paste backfill in column experiments," Engineering Geology, vol. 170, pp. 11-23, 2014.

[9] A. Kesimal, E. Yilmaz, B. Ercikdi, I. Alp, and H. Deveci, "Effect of properties of tailings and binder on the short-and longterm strength and stability of cemented paste backfill," Materials Letters, vol. 59, no. 28, pp. 3703-3709, 2005.

[10] M. L. Walske, H. McWilliam, J. Doherty, and A. Fourie, "Influence of curing temperature and stress conditions on mechanical properties of cementing paste backfill," Canadian Geotechnical Journal, vol. 53, no. 1, pp. 148-161, 2015.

[11] N. Abdul-Hussain and M. Fall, "Thermo-hydro-mechanical behaviour of sodium silicate-cemented paste tailings in column experiments," Tunnelling and Underground Space Technology, vol. 29, pp. 85-93, 2012.

[12] C. Hou, W. Zhu, B. Yan, K. Guan, and J. Du, "Influence of binder content on temperature and internal strain evolution of early age cemented tailings backfill," Construction and Building Materials, vol. 189, pp. 585-593, 2018.

[13] E. Yilmaz, T. Belem, and M. Benzaazoua, "Effects of curing and stress conditions on hydromechanical, geotechnical and geochemical properties of cemented paste backfill," Engineering Geology, vol. 168, pp. 23-37, 2014.

[14] H. Jiang, M. Fall, and L. Cui, "Yield stress of cemented paste backfill in sub-zero environments: experimental results," Minerals Engineering, vol. 92, pp. 141-150, 2016.

[15] H. F. Li, M. Q. Chen, B. A. Fu, and B. Liang, "Evaluation on the thermal and moisture diffusion behavior of sand/bentonite," Applied Thermal Engineering, vol. 151, pp. 55-65, 2019.

[16] M. Pokharel and M. Fall, "Combined influence of sulphate and temperature on the saturated hydraulic conductivity of hardened cemented paste backfill," Cement and Concrete Composites, vol. 38, pp. 21-28, 2013.

[17] D. Wu, M. Fall, and S.-J. Cai, "Coupled modeling of temperature distribution and evolution in cemented tailings backfill structures that contain mineral admixtures," Geotechnical and Geological Engineering, vol. 30, no. 4, pp. 935961, 2012.

[18] O. Nasir and M. Fall, "Coupling binder hydration, temperature and compressive strength development of underground cemented paste backfill at early ages," Tunnelling and Underground Space Technology, vol. 25, no. 1, pp. 9-20, 2010.

[19] D. Wu, M. Fall, and S.-J. Cai, "Numerical modelling of thermally and hydraulically coupled processes in hydrating cemented tailings backfill columns," International Journal of Mining, Reclamation and Environment, vol. 28, no. 3, pp. 173-199, 2014.

[20] L. Cui and M. Fall, "A coupled thermo-hydro-mechanicalchemical model for underground cemented tailings backfill," Tunnelling and Underground Space Technology, vol. 50, no. 50, pp. 396-414, 2015.

[21] O. Nasir and M. Fall, "Modeling the heat development in hydrating CPB structures," Computers and Geotechnics, vol. 36, no. 7, pp. 1207-1218, 2009.

[22] G. De Schutter and L. Taerwe, "General hydration model for portland cement and blast furnace slag cement," Cement and Concrete Research, vol. 25, no. 3, pp. 593-604, 1995.

[23] G. De Schutter and L. Taerwe, "Degree of hydration-based description of mechanical properties of early age concrete," Materials and Structures, vol. 29, no. 6, pp. 335-344, 1996.

[24] J. K. Kim, S. H. Han, and K. M. Lee, "Estimation of compressive strength by a new apparent activation energy function," Cement and Concrete Research, vol. 31, no. 2, pp. 217-225, 2001.

[25] K. O. Kjellsen and R. J. Detwiler, "Later-age strength prediction by a modified maturity model," ACI Materials Journal, vol. 90, no. 3, pp. 220-227, 1993.

[26] J. L. Poole, K. A. Riding, K. J. Folliard, M. C. G. Juenger, and A. K. Schindler, "Methods for calculating activation energy for Portland cement," ACI Materials Journal, vol. 104, no. 1, pp. 303-311, 2007.

[27] A. K. Schindler and K. J. Folliard, "Heat of hydration models for cementitious materials," ACI Materials Journal, vol. 102, no. 1, pp. 24-33, 2005.

[28] K. O. Kjellsen, R. J. Detwiler, and O. E. Gjørv, “Development of microstructures in plain cement pastes hydrated at different 
temperatures," Cement and Concrete Research, vol. 21, no. 1, pp. 179-189, 1991.

[29] W. Saengsoy, Effect of Curing Conditions on Hydration Reaction and Compressive Strength Development of Fly AshCement Pastes, Division of Solid Waste, Resources and Geoenvironmental Engineering, Hokkaido University, Sapporo, Japan, 2008

[30] Z. P. Bažant and L. J. Najjar, "Nonlinear water diffusion in nonsaturated concrete," Matériaux et Construction, vol. 5, no. 1, pp. 3-20, 1972.

[31] J. Zhang, K. Qi, and Y. Huang, "Calculation of moisture distribution in early-age concrete," Journal of Engineering Mechanics, vol. 135, no. 8, pp. 871-880, 2009.

[32] J. Zhang, J. Wang, and Y. Gao, "Moisture movement in earlyage concrete under cement hydration and environmental drying," Magazine of Concrete Research, vol. 68, no. 8, pp. 391-408, 2016.

[33] L. Cui and M. Fall, "An evolutive elasto-plastic model for cemented paste backfill," Computers and Geotechnics, vol. 71, pp. 19-29, 2016.

[34] A. M. Galaa, B. D. Thompson, M. W. Grabinsky, and W. F. Bawden, "Characterizing stiffness development in hydrating mine backfill using ultrasonic wave measurements," Canadian Geotechnical Journal, vol. 48, no. 8, pp. 1174-1187, 2011.

[35] Z. Bittnar, "Microstructure-based micromechanical prediction of elastic properties in hydrating cement paste," Cement and Concrete Research, vol. 36, no. 9, pp. 1708-1718, 2006.

[36] A. Boumiz, C. Vernet, and F. C. Tenoudji, "Mechanical properties of cement pastes and mortars at early ages evolution with time and degree of hydration," Advanced Cement Based Materials, vol. 3, no. 3-4, pp. 94-106, 1996.

[37] C. M. Sayers and R. L. Grenfell, "Ultrasonic propagation through hydrating cements," Ultrasonics, vol. 31, no. 3, pp. 147-153, 1993.

[38] D. Wu, T. Deng, and R. Zhao, "A coupled THMC modeling application of cemented coal gangue-fly ash backfill," Construction and Building Materials, vol. 158, pp. 326-336, 2018.

[39] T. C. Powers and T. L. Brownyard, "Studies of the physical properties of hardened Portland cement paste," ACI Journal Proceedings, vol. 43, no. 9, pp. 249-336, 1947.

[40] S. Kamali, M. Moranville, E. Garboczi, S. Prené, and B. Gérard, "Hydrate dissolution influence on the Young's modulus of cement pastes," in Proceedings if the Fracture Mechanics of Concrete Structures (FraMCoS-V), Routledge, Vail, CO, USA, pp. 631-638, January 2004.

[41] P. Choktaweekarn and S. Tangtermsirikul, "A model for predicting coefficient of thermal expansion of cementitious paste," ScienceAsia, vol. 35, no. 1, pp. 57-63, 2009.

[42] H. J. H. Brouwers, "The work of powers and brownyard revisited: part 1," Cement and Concrete Research, vol. 34, no. 9, pp. 1697-1716, 2004. 